\title{
Association of children immunization coverage with parental characteristics in a rural area of Bangladesh
}

\author{
N Nazneen ${ }^{1}$, MS Laskar ${ }^{2}$, PP Barua ${ }^{3}$, S Farjan", M Parveen ${ }^{5}$, MN Alam ${ }^{6}$
}

\begin{abstract}
The purpose of the cross sectional descriptive type of study was to document the childhood immunization coverage and its association with parental socio-demographic characteristics. For this, 160 parents of 160 children from a selected rural area of Chittagong, Bangladesh were selected by purposive sampling technique and data were collected by face to face interview using a semi-structured questionnaire. Immunization coverage of the children was about $82 \%$. Parental age, gender and their decision (governmental or private service from where immunization done) were significantly associated with the children immunization coverage ( $p<$ $0.01, p<0.01$ and $p<0.05$, respectively). The result may be helpful to policymakers for future planning and implementation of children immunization programme to improve children immunization coverage in Bangladesh.
\end{abstract}

Key words: Children immunization, parental characteristics, association, Bangladesh.

\section{Introduction}

Disease prevention should be at the forefront of any healthcare strategy now a day. The morbidity and mortality caused by diseases and rising costs of treating them requires focusing more on their prevention. Immunization is among the most successful components of preventive medicine. In the United States, where accurate recording of immunization and reporting of diseases is in place, most vaccine-preventable diseases are at or near record lows. ${ }^{1}$ Despite successes in control of vaccine preventable diseases in the developed world, diseases such as measles still require better control particularly in developing countries with limited resources. ${ }^{2}$
In May 1974, World Health Organization (WHO) officially launched a global programme on vaccination named as Expanded Programme on immunization (EPI) to protect all children of the world against vaccine preventable diseases. EPI is a successful programme in Bangladesh. It resulted in reduction of infant and neonatal mortality tremendously. Vaccines are among the most effective prevention. ${ }^{3}$ It has significant achievement in comparison with other South Asian countries. By virtue of this programme in Bangladesh infant mortality rate (IMR) and neonatal mortality rate (NMR) reduced to $31 / 1000$ and $23 / 1000$ live births, respectively. ${ }^{4}$ It was found in a study that formal education of women has a great

\footnotetext{
1. N Nazneen, MBBS, MPH, Assistant Professor, Gazi Medical College, Khulna

2. MS Laskar, MD, MPH, PhD, Professor of Community Medicine, Gazi Medical College, Khulna

3. PP Barua, MBBS, MPH, Associate Professor of Community Medicine, Rangamati Medical College, Rangamati

4. S Farjan, MBBS, MPhil, Assistant Professor of Anatomy, Gazi Medical College, Khulna

5. M Parveen, MBBS, MPhil, Assistant Professor of Biochemistry, Gazi Medical College, Khulna

6. MN Alam, MBBs, DCH, Assistant Professor of Pediatrics, Cox's Bazar Medical College, Cox's Bazar
} 
impact on the child health as educated women are more concerned about the immunization of their children. Educated women perform protective functions related their children health but education is also related to awareness on immunization schedule. ${ }^{5}$ Parents understanding importance of immunization lead to timely vaccination of their children. The study highlighted that profession of the parents also influence on immunization process. It is already understood that people with lower income level or socio demographic status are less chance to get vaccinated their children on due dates because they have to take off for timely immunization process which ultimately burdensome for them. It has been learnt that parents with high income and higher positions in the society are highly associated to fulfill their responsibility related to immunization for minimizing children mortality, morbidity, and disability.

The purpose of the present study was to document the childhood immunization coverage and its association with parental socio-demographic characteristics.

\section{Materials and Method}

This descriptive study was carried out in a selected rural area of Chittagong. Parents of the children up to the age of 5 were interviewed for the purpose of this study. It was possible to get information on EPI coverage of 160 children from their parents and about parental characteristics. The respondents were selected by purposive sampling technique and data were collected by face to face interview using a semi-structured questionnaire. All the subjects were informed in details about the nature and purpose of the study. After collection of the data were edited, verified for its consistency. Then data analysis was done by using SPSS version 19 for windows. ${ }^{6}$ Statistical significance was measured according to the objectives of the study. Statistical analysis was done using appropriate tests of significance e.g. Chi-square test and if necessary Fisher's-exact test. The association was also tested using Pearson correlation test. Statistical significance was considered when $p$ value less than 0.05 .

\section{Results}

Parental characteristics and children immunization coverage are shown in Table 1. The mean (SD) age of the respondents were 31.9 (9.6) years. The female respondents were 88 $(55 \%)$. Most of the respondent's religion was Islam, (70\%). Immunization coverage of the children was about $82 \%$. Table 2 shows the cross tabulation on children immunization status and parental characteristics. Parental age, gender and their decision (governmental or private service from where immunization done) were significantly associated with the children immunization coverage $(p<$ $0.01, p<0.01$ and $p<0.05$, respectively). Table 3 shows Pearson correlation between children immunization status and parental characteristics was also statistically significant for parental age, gender, their decision (governmental or private service from where immunization done) and socio-economic status $(p<0.01, p<0.01, p<0.05, p<0.05$, respectively).

\section{Discussion}

The results of the study offer insight into the association of children immunization with parental socio-economic characteristics and can be utilized to conduct larger community based survey in order to intervene and improve vaccination status of the population.

Table 1. Parental characteristics and children immunization coverage, $(n+160)$

\begin{tabular}{lr}
\hline Characteristics & $\begin{array}{r}\text { Mean (SD)/ } \\
\text { Number (\%) }\end{array}$ \\
\hline Parental age, years & $31.9(9.6)$ \\
Parental gender, female & $88(55.0)$ \\
Parental religion- Islam & $112(70.0)$ \\
Received information on immunization from any source & $98(61.3)$ \\
Immunization coverage among the children & $131(81.9)$ \\
Adverse effect following immunization & $51(31.9)$ \\
Managed adverse effect following immunization & $45(28.1)$ \\
\hline
\end{tabular}


Table 2. Cross tabulation on children immunization status and parental characteristics, $(n=160)$

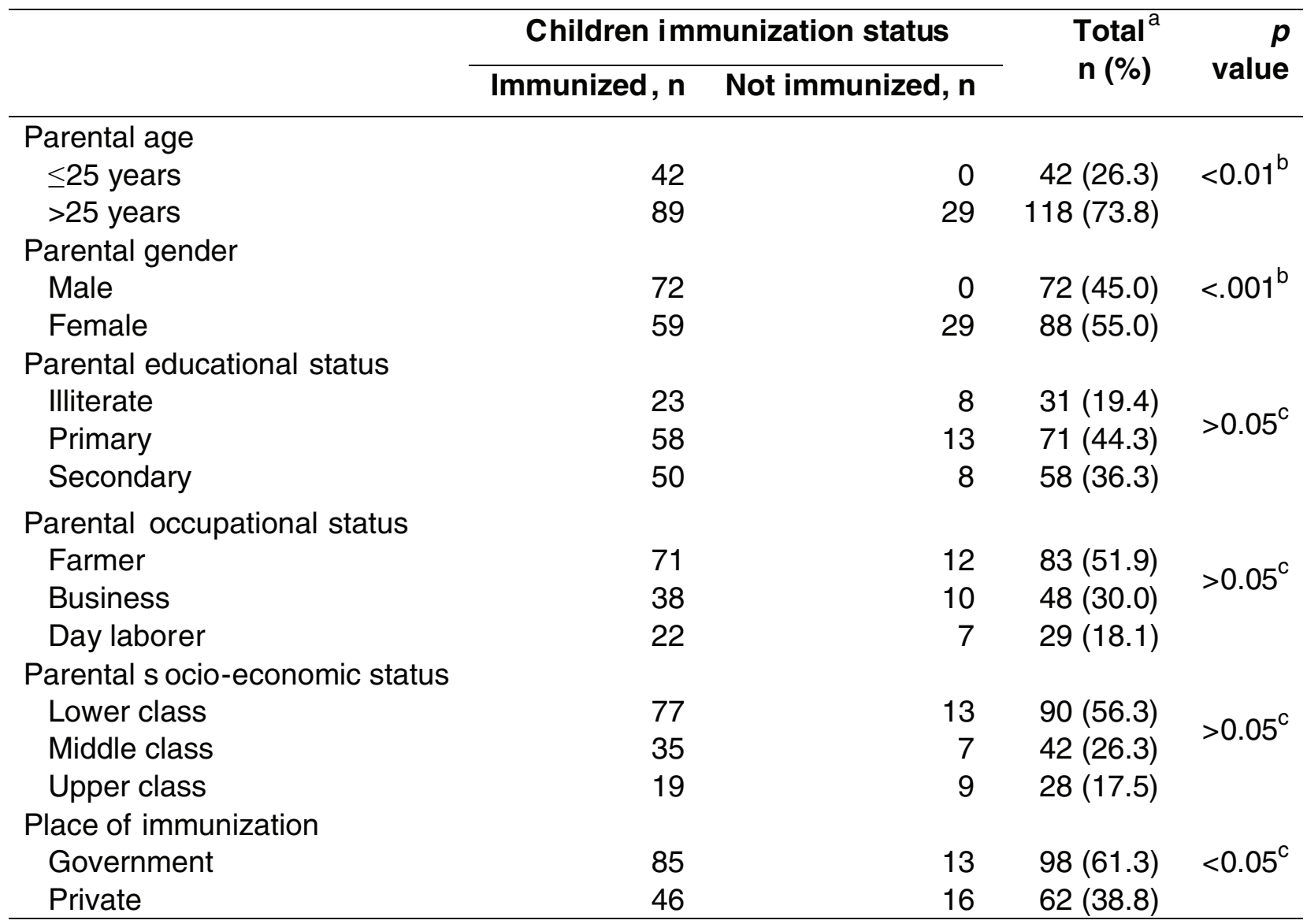

n, number, ${ }^{\text {a. }}$ Total may not show $100 \%$ as rounding was not done ${ }^{\text {b: }}$ Fisher's exact test, ${ }^{\text {c: }}$ Chisquare test.

Table 3. Pearson correlation coefficients between children immunization status and parental characteristics, $(n=160)$

\begin{tabular}{lcc}
\hline & Children immunization status & $\boldsymbol{p}$ value \\
\hline Parental age & -0.260 & $<0.01$ \\
Parental gender & 0.197 & $<0.01$ \\
Parental educational status & 0.109 & $>0.05$ \\
Parental occupational status & -0.101 & $>0.05$ \\
Parental socio-economic status & -0.153 & $<0.05$ \\
Place of immunization & 0.159 & $<0.05$ \\
\hline
\end{tabular}


Over $89 \%$ of respondents were in favor of vaccination and believed that it prevents disease. This study shows that socioeconomic status significantly associated with child immunization. This findings is in line with those reported earlier in the country in which a majority of respondents acknowledged the importance of immunization. $^{7}$

The relationship between immunization and education level of parents indicated that majority of the educated parents immunized their children. The results show that $80.6 \%$ of the educated parents immunized their children as compared to $19.4 \%$ of uneducated parents. The other study explored the hypothesis that educated women on formal grounds results in enhanced child survival due to awareness of the shielding function of the major childhood immunizations. Education is also correlated with enhanced consciousness of proper immunization schedules.

WHO reported that million of the children are saved due to immunization every year around the world; this is process in which a person gets immunization against infectious diseases. The research was particularly conducted to see the minorities' attitude towards immunization. In the $20^{\text {th }}$ century, there has been a big revolution in health sector in which one of the important factors is immunization. Small pox and polio have been wiped out through vaccination. Likewise measles, diphtheria, and other diseases have been controlled. ${ }^{8}$

Recently, a study on socio-demographic differentials in coverage of basic child immunization was conducted in India and the states of Bihar and Gujarat using three rounds of National Family Health Survey data. Results indicated that there has been a considerable increase in partial immunization in most of the states, but the increase in full immunization coverage is relatively slow in most of the states. In conjunction with standard of living, mother's education, mass media exposure, and availability of health card is a significant predictor in explaining the full immunization coverage irrespective of time..$^{9-11}$

The other study assessed the influence of resources and households' structure on immunization in Jamaica, Trinidad, and Tobago. This study compared various households like single parents, double parents and extended, also measured income level and its effect on immunization. They also tried to see effect of resources and income on immunization. The major policy implications was to come into sight from this study that income status and household structure are vital for understanding of child immunization in the Caribbean. ${ }^{12,13}$

Respondents were noted to be well informed about possible side effects of immunization that include fever and rash. It is to be noted that friends and parents, rather than physicians, are a source about side effects of immunization for these patients. Concerns regarding possible side effects from immunization and its adverse impact on immunization coverage have been reported earlier. ${ }^{14}$

Among the hurdles pointed out about immunization by the respondents include those such as lack of hinds which are difficult to overcome in the near future but also those which can be successfully controlled such as lack of awareness and education about immunization. Such barriers have also been reported earlier. ${ }^{15}$

It should not be of surprise that the factors reported for promotion of immunization coverage by respondents include improving awareness and educating the mass people and mothers and the provision of facilities for immunization. These factors are already known to positively impact immunization coverage and therefore it is important to work on these in order to improve immunization coverage to a more satisfactory level among our population. The role of physician is also very important in promotion of immunization among the population. ${ }^{15,16}$

\section{Conclusion}

The purpose of the cross sectional descriptive type of study was to document the childhood immunization coverage and its association with parental socio-demographic 
characteristics. For this, 160 parents of 160 children from a selected rural area of Chittagong, Bangladesh were selected by purposive sampling technique and data were collected by face to face interview using a semi-structured questionnaire. Immunization coverage of the children was about $82 \%$. Parental age, gender and their decision (governmental or private service from where immunization done) were significantly associated with the children immunization coverage. The result may be helpful to policymakers for future planning and implementation of children immunization programme to improve children immunization coverage in Bangladesh.

\section{References}

1. Orenstein WA, Douglas RG, Rodewald LE, et al. Immunizations in the United States: success, structure, and stress. Health Aff (Millwood) 2005;24:599-610.

2. Moss WJ, Griffin DE. Global measles elimination. Nat Rev Microbiol 2006;4:900-8.

3. Hyatt RR, Allen SM. Disability as a "family affair": parental disability and childhood immunization. Medical Care 2005;43:600-6.

4. National Health Bulletin, Bangladesh. 2015.

5. Kim S, Ugurbil K. (1997). Functional magnetic resonance imaging of the human brain. $J$ Neurosci Methods 1997;74(1):229-43.

6. IBM SPSS Statistics 19. SPSS Inc. SPSS Advanced Models. SPSS 19. Chicago, IL, USA, 2010.

7. Streatfield K, Singarimbun M, Diamond I. Maternal education and child immunization. Demography 1990;27(3):447-55.
8. World Health Organization. State of the world's vaccines and immunization. [report] World Health Organization, Geneva, Switzerland, 2010.

9. Kumar A, Mohanty S. State of child health among poor and non-poor in urban India. Genus 2011;67 (1):1-19.

10.Steele F, Diamond I, Amin S. Immunization uptake in rural Bangladesh: a multilevel analysis. Journal of the Royal Statistical Society. Series A (Statistics in Society) 1996;159(2):289-99.

11. National immunization program schedule for Victoria from July 2007. [report] Department of Health, Victoria, Australia, 2007.

12. Tinkew B, Gordon FDJ, Jacinta. Do household structure and household economic resources predict childhood immunization? Evidence from Jamaica and Trinidad and Tobago. Popul Res Policy Rev 2005;24(1):27-57.

13.Pande RP. Selective gender differences in childhood nutrition and immunization in rural India: the role of siblings. Demography 2003;40(3):395-418.

14. Buireiy J, La Vincente S, Andrews R, et al. Adverse events following immunisation: desperately seeking surveillance. Lancet Infect Dis 2006;6:680-1.

15. Topuzoglu A, Ay P, Hidiroglu S, et al. The barriers against childhood immunizations: a qualitative research among socioeeonomically disadvantaged mothers. Eur J Public Health 2006: [Epubaheadofprint].

16. Nowalk MP, Baidella IJ, Zimmerman RK, et al. The physician's office: can it influence adult immunization rates? Am J Manag Care 2004;10:13-9.

\section{Suggestion for citation of the above:}

Nazneen N, Laskar MS, Barua PP, Farjan S, Parveen M, Alam MN. Association of children immunization coverage with parental characteristics in a rural area of Bangladesh. Mediscope 2017;4(1):25-9. 